Theories \& Applications, the International Edition

Printed Version : (ISSN 2090-5262)

Online Version : (ISSN 2090-5270)

July 2014, Volume 4, No. 2 Pages (117 - 123)

\title{
Effects of Using the Ergometer on Improving the Efficiency of Learning for Rowers.
}

\author{
Dr. Manal Goaida Abu Al-Magd \\ Assistant professor, Curricula and Methods of Teaching Dept, Faculty of Physical Education - Tanta University, Egypt.
}

\begin{abstract}
The current research aims at identifying the effects of using ergometers on improving the efficiency of learning in young rowers. The researcher used the quasi-experimental approach (two-group design) with control and experimental groups. Sample included (28) rowers who were randomly chosen from the sports clubs of Alexandria. All sample members were under 18 years and free of injuries. They were divided into two groups (experimental $=17$, control $=11$ ). The researcher concluded that there are statistically significant differences between the post-measurements of the experimental and control groups on Boat speed, Stroke frequency, Boat speed during stroke (paddle cycle) and Duration of paddle in water, in favor of the experimental group as $(t)$ calculated values ranged between 3.231 and $5.315(P \leq 0.05)$.
\end{abstract}

Introduction:

$\mathrm{O}$ ur modern age is characterized by revolutionary scientific leaps that affect all aspects of life. Theses modern trends and ideas affect life's objectives and approaches. Modern philosophy of physical education is totally consistent with modern developments in sciences, arts and motor activities. Its approaches are also consistent with growth stages and are based on modern developments of the educational process.

Education is the main axis for changing the future as it is the means for preparing new generations and reconstructing the society according to the demands of the age. Through education, we make a learner who is able to understand his/her rights and duties (21:11).

Learning in aquatic sports is very difficult due to the differences of the aquatic medium from other sports as its properties and ways of dealing are completely different. It is from the unfamiliar media that may raise fear makes skills slow to acquire due to its difficulty level and complexity. This requires thinking of alternative means of teaching these skills to help learners overcome such difficulties and achieve well-developed stages of performance and automated ideal performance of these skills. This cannot be achieved unless skills are well-mastered and maintained smoothly and sequentially. There are several studies that assert the importance of using alternative teaching aids in facilitating learning for beginners like Nasima Waly (2001) (20), Maisa Fouad (2005) (4) and Marwa Hassan (2010) (15).

These studies indicate the positive effect of alternative aids in the educational process for all sports. Rowing is an aquatic sport that is performed from a boat through using paddles' strokes that lead to moving the boat.

\section{Research Problem:}

Rowing is a sport that requires special physical, technical and functional abilities due to its different medium. Rowing did not receive enough attention in the related literature, especially improving performance and increasing boat speed. This is due to the fact that rowing is a difficult sport to learn as learning requires prolonged time and several procedures to improve the rowers' performance level. Learning is done traditionally in a specific boat with larger dimensions and more stability for learning basic skills. This boat allows the instructor to move among rowers and correct any mistakes. Then, rowers move into regular boats. Most of the time, this shift leads to confusion of performance and weakness of learning. Recently, several static rowing machines appeared that greatly resemble the regular boat. Ergometers are competitive machines that can be used in championships approved by the international federation of rowing. It can be used in training as the dry-land activity resembles the in-water activity. In addition, it can be used in learning basic skills and is considered as a valid measurement for learning and an important indicator for achieving objectives. Furthermore, dry-land training via ergometer is ideal for improving rowing technique, especially body positions. Abd El-Fattah \& Hasanain (1997) and Fritsch (1990) indicated that ergometers are the most specific machines for rowing as work is at the same direction of real activity and the device provides instant feedback about maximum effective functional strength of rowing (1:79) (9)

There are several studies indicating the importance of using ergometers in rowing, either for physiological measurements of for functional prediction, like Ibrahim Al-Roquaiy (2012) (6) and Kane \& Jensen (2008) (12). Accordingly, the ergometer is considered as a valid tool for learning rowing in beginners as it adds excitement and helps avoiding 
boredom and fatigue. The researcher thinks that the staticergometer can be used as an intermediate step between learning boats and regular boats to increase the efficiency of learning. This helps rowers to find an automated, wellcalibrated and error-free means for improving the efficiency of using the regular boats. This, in turn, improves the performance level and decreases time and effort used for stimulating rowers for better performance.

\section{Aim:}

The current research aims at identifying the effects of using ergometers on improving the efficiency of learning in young rowers.

\section{Hypothesis:}

There are statistically significant differences between the post-measurements of the control and experimental groups on performance variables in favor of the experimental group.

\section{Terminology:}

\section{The Ergometer:}

It is an erogmeter boat with approved competitions that can be used for competition and measurement as well. The term is disyllabic (ergo means work and meter means measure). Through this device we can control stroke rate, intensity, and resistance and performance duration. This makes it easy for rowing coaches and instructors to unify physical load and acquire physiological tests and measurements (1:251)

\section{Review of Literature:}

1. Mostafa Saif (2011) studied the effects of some specific drills on improving rebound moves and its relation to the digital achievement of young rowers. The researcher used the quasi-experimental approach on sample of (32) rowers divided into two groups (control/experimental). The researcher concluded statistically significant differences in favor of the experimental group on $(2000 \mathrm{~m})$ time with no statistically significant differences on $(500 \mathrm{~m})$ and $(2000 \mathrm{~m})$ choice of speed. (18)

2. Ibrahim Al-Roquaiy (2012) predicted some physical and functional aspects of young rowers using the ergometer. The researcher used the descriptive (survey) approach on a randomly chosen sample $(n=60)$. The researcher concluded that speed, leg strength, vital capacity, BMI and $\mathrm{VO} 2_{\max }$ were good predictors for some functional aspects of young rowers for $(500 \mathrm{~m})$ distance. (6)

3. Husain Abd El-Salam (2010) studied the effectiveness of an intensive training program on some physical variables and the digital level of $2000 \mathrm{~m}$ race for young rowers. The researcher used the quasi-experimental approach on sample of (19) rowers divided into two groups (control $=11$ /experimental $=8$ ). The researcher concluded statistically significant differences in favor of the experimental group on all physical variables except for strength endurance and 20sec running. The program improved the digital level of $2000 \mathrm{~m}$ race (3).

4. Aklusiwiz and Sitkowski (1998) studied the evaluation and replication of results obtained using two different types of ergometers common among rowers. The researchers aimed at identifying anaerobic capacity, $\mathrm{VO} 2_{\max }$ and achievement level using a simulated $2000 \mathrm{~m}$ race during (6) minutes. The researchers used the descriptive approach on a sample of (15) rowers. Results indicated that anaerobic capacity and $\mathrm{VO} 2_{\max }$ have direct effects on the achievement level of rowers. (13)

5. Kane et al (2008) examined the effects of two resistances, or "drag factors" on selected physiological variables during incremental progressive rowing tests (seven 3-min stages) on a Concept $2 ®$ ergometer. Subjects were seven male and seven female university club rowers. Their mean age, body mass and height were $19.6 \pm 1.5$ years, $72.7 \pm 8.0 \mathrm{~kg}$, and $172.2 \pm 7.5 \mathrm{~cm}$, respectively. Progressive tests were conducted using drag factors 100 (D100) and 150 (D150) before the spring racing season. Values were determined for the following physiological variables: ventilation $(\mathrm{V} \cdot \mathrm{E})$, oxygen uptake (V.O2), heart rate (HR), blood lactate concentration (BLC), respiratory exchange ratio (R) and rowing economy (W/V·O2). Comparisons across all six submaximal stages showed no significant difference between D100 and D150 for any of the variables measured $(\mathrm{p}>.05)$. Maximal V-Emax was significantly greater at D100 than D150 (p <.02). Maximal V.O2, HR, BLC, R, stroke rate $(\mathrm{SR})$ and $W / \mathrm{V} \cdot \mathrm{O} 2$ were greater at $\mathrm{D} 100$ than at D150, though not significantly so. The mean D100 D150 differences in V.E and SR for each stage were significantly correlated $(\mathrm{r}=0.76, \mathrm{p}<.01)$, suggesting drag factor may affect V.E via SR. (12)

6. Benson et al (2011) made a comparison of rowing on a Concept 2 stationary and dynamic ergometer Biomechanical and physiological responses to rowing $1000 \mathrm{~m}$ at a power output equivalent to a $2000 \mathrm{~m}$ race were compared in 34 collegiate rowers (17 women, 17 men) rowing on a stationary and dynamic Concept 2 ergometer. Stroke ratio, peak handle force, rate of force development, impulse, and respiratory exchange ratio decreased by 15.7 , $14.8,10.9,10.2$ and $1.9 \%$, respectively, on the dynamic ergometer. In contrast, percent time to peak force and stroke rate increased by 10.5 and $12.6 \%$, respectively, during dynamic ergometry; the changes in stroke rate and impulse were greater for men than women. Last, VO2 was $5.1 \%$ higher and efficiency 
$5.3 \%$ lower on the dynamic ergometer for men. Collegiate rowers used higher stoke rates and lower peak stroke forces to achieve a similar power output while rowing at race pace on the dynamic ergometer, which may have increased the cardiopulmonary demand and possibly reduced force production in the primary movers. Differences were more pronounced in males than females; this dichotomy may be more due to dynamic ergometer familiarity than sex. (7)

Methods:

\section{Approach:}

The researcher used the quasi-experimental approach (twogroup design) with control and experimental groups.

\section{Sample:}

Sample included (28) rowers who were randomly chosen from the sports clubs of Alexandria. All sample members were under 18 years and free of injuries. They were divided into two groups $($ experimental $=17$, control $=11)$.

\section{Pre-measurements:}

After review of literature $(3,10,9,11$ and 16$)$, the researcher identified the suitable tests for measuring physical components of rowing. The researcher homogenized sample members as shown in table (1)

Table (1)

mean, median, loom, $\mathrm{SD}$, Squewness and flatness of variables affecting rowing performance $(\mathrm{n}=\mathbf{2 8})$

\begin{tabular}{|c|c|c|c|c|c|c|}
\hline Variables & Mean & Median & Loom & SD & Squewness & Flatness \\
\hline Weight & 72.709 & 72.890 & 70.04 & 4.364 & 0.447 & 0.049 \\
\hline Height & 173.071 & 171.250 & 182.00 & 5.685 & 0.661 & -1.244 \\
\hline Sitting height & 87.071 & 88.00 & 86.00 & 2.379 & -0.886 & 0.038 \\
\hline Arm length & 83.517 & 81.500 & 81.00 & 4.372 & 0.343 & -1.374 \\
\hline Leg length & 89.482 & 88.500 & 88.500 & 3.767 & 0.150 & -0.495 \\
\hline Ratio of sitting height & 51.365 & 51.320 & 59.59 & 3.869 & 1.230 & 0.747 \\
\hline Right grip strength & 39.642 & 38 & 38 & 5.390 & 0.473 & -0.259 \\
\hline Lift grip strength & 37.071 & 34 & 34 & 6.632 & 5.390 & 0.674 \\
\hline Back strength & 94.642 & 100 & 80 & 13.806 & -0.307 & -1.179 \\
\hline Leg strength & 104.642 & 105 & 105 & 21.727 & 0.268 & 0.213 \\
\hline
\end{tabular}

Table (1) indicated sample homogeneity as squewness and flatness values are in normal range.

Table (2)

mean, SD and $(t)$ values for the pre-measurements of the two groups on all physical variables

\begin{tabular}{|c|c|c|c|c|c|}
\hline \multirow{2}{*}{ Variables } & \multicolumn{2}{|c|}{ Experimental } & \multicolumn{3}{c|}{ Control } \\
\cline { 2 - 6 } & Mean & SD & Mean & SD & \\
\hline Weight & 73.102 & 4.374 & 72.101 & 4.486 & 0.586 \\
\hline Height & 173.382 & 5.896 & 172.590 & 5.589 & 0.354 \\
\hline Sitting height & 86.941 & 2.480 & 87.272 & 2.316 & -0.354 \\
\hline Arm length & 83.352 & 4.418 & 83.772 & 4.502 & -0.244 \\
\hline Leg length & 89.58 & 3.957 & 89.318 & 3.635 & 0.182 \\
\hline Ratio of sitting height & 51.022 & 3.725 & 51.895 & 4.208 & -0.576 \\
\hline Right grip strength & 39.882 & 5.588 & 39.272 & 5.312 & 0.287 \\
\hline Lift grip strength & 37.176 & 6.857 & 36.909 & 6.594 & 0.102 \\
\hline Back strength & 95.00 & 13.919 & 94.090 & 14.286 & 0.167 \\
\hline Leg strength & 106.176 & 21.903 & 102.272 & 22.289 & 0.457 \\
\hline
\end{tabular}

Table (2) indicated no statistically significant differences between the pre-measurements of the experimental and control groups. This indicates that both groups are homogenous.
Data collection tools:

After review of related literature (12, 3, 18 and 6), the researcher identified the following tools and equipments to be used in this study: 
- A medical balance for weight

- A restameter for heights

- A manometer for grip strength

- A dynamometer for back and leg strength

- A rowing ergometer

- A measuring tape

- A stop-watch

- A data recording form

\section{Pilot Study:}

The researcher performed the pilot study from 28-6-2012 to 30-6-2012 on a pilot sample $(n=6)$ to achieve the following aims:

1. Validating tools and equipments

2. Assuring safety procedures of measurement and testing

3. Identifying any problems that may face main application

4. Training assistants on measurement techniques

The recommended educational program with the ergometer:

The following are the aims of the program:

\section{Cognitive aims:}

1. Educating beginner rowers about the importance of rowing

2. Providing beginner rowers with knowledge and information about rowing skills

3. Providing beginner rowers with the ability to observe and think

4. Providing beginner rowers with knowledge about using equipments that aid learning

\section{Technical aims:}

1. The beginner should acquire new learning methods

2. The beginner should acquire the ability to differentiate right from wrong

3. The beginner should relate information with performance through the ergometer

4. The beginner should acquire the ability to imagine and describe the correct performance

\section{Program bases:}

1. Considering individual differences

2. Providing space and equipments needed for application

3. Considering in-water safety procedures

4. The content should be suitable for the skills to be learned

5. The program should be simple and interesting

6. Considering gradual progress from easy to difficult

7. The program should enhance the inter- and intrapersonal relations

\section{Capabilities:}

The program uses the following:

- Illustrations

\section{Content:}

- Computer projections via $\mathrm{CD}$

The program content includes basic rowing skills that beginners should learn as a preliminary phase to progress towards competitive level.

Through review of related literature $(6,18,2$ and 16), the researcher identified basic skills needed for beginning rowers according to their performance level.

Table (3)

Schedule of the program

\begin{tabular}{|c|c|}
\hline Content & Duration \\
\hline Number of weeks & 12 weeks \\
\hline Units per week & 3 units \\
\hline Unit duration & $90 \mathrm{~min}$ \\
\hline Number of units & $3 \times 12=36$ units \\
\hline Total duration of units & $90 \times 36=3240 \mathrm{~min}$ \\
\hline
\end{tabular}

\section{Main application:}

The recommended program using the erogmeter was applied to the experimental group from 1-7-2012 to 23-9-2012 according to the regular training schedule of the rowing team. The researcher considered that both groups (control/experimental) should use the same warm-up, physical preparation and cool down. As for the main part, the experimental group should use the ergometer while the control group should use the regular training program. 
Table (4)

Time Schedule of the unit

\begin{tabular}{|c|c|c|c|}
\hline Part & Duration & Experimental & Control \\
\hline Warm up & $15 \mathrm{~min}$ & $\begin{array}{l}\bullet \text { Preparing working muscules } \\
\bullet \text { Jogging and arm/leg stretches }\end{array}$ & Same as experimental \\
\hline $\begin{array}{c}\text { Physical } \\
\text { preparation }\end{array}$ & $15 \mathrm{~min}$ & Strength drills for arms and legs & Same as experimental \\
\hline Main part & $\mathbf{5 0 ~ m i n}$ & $\begin{array}{l}\bullet \text { Ergometer drills according to the program } \\
\bullet \text { In-water drills using the boat }\end{array}$ & In-water drills using the boat \\
\hline Cool down & $10 \mathrm{~min}$ & Small game - light drills & Same as experimental \\
\hline
\end{tabular}

\section{Post-measurements:}

At the end of application, the researcher applied the postmeasurements on 24-9-2012 for both groups.

Results:
Statistical treatment:

The researcher used SPSS software to calculate the following: mean - median - SD - squewness - flatness loom - LSD - (t) value - variance analysis.

Table (5)

means, SD and (t) values for both groups on rowing performance variables

\begin{tabular}{|c|c|c|c|c|c|}
\hline \multirow{2}{*}{ Variables } & \multicolumn{2}{|c|}{ Experimental $(\mathrm{n}=17)$} & \multicolumn{2}{|c|}{ Control $(\mathrm{n}=11)$} & \multirow{2}{*}{$(\mathrm{t})$} \\
\cline { 2 - 6 } & Mean & SD & Mean & SD & \\
\hline Boat speed & 4.60 & $\mathbf{0 . 3 8 3}$ & 3.901 & $\mathbf{0 . 3 3 7}$ & $3.231^{*}$ \\
\hline Stroke frequency & 38.882 & 4.029 & 33.363 & $\mathbf{0 . 8 0 9}$ & $4.456^{*}$ \\
\hline Stroke distance & 715.764 & 31.661 & $\mathbf{7 2 8 . 0 0}$ & 48.257 & $-\mathbf{0 . 8 1 3}$ \\
\hline Boat speed during stroke (paddle cycle) & 4.640 & $\mathbf{0 . 4 1 9}$ & 4.084 & $\mathbf{0 . 2 5 0}$ & $3.946 *$ \\
\hline Stroke tempo & $\mathbf{0 . 7 9 1}$ & $\mathbf{0 . 1 8 0 0}$ & $\mathbf{0 . 9 0 8}$ & $\mathbf{0 . 1 6 5}$ & -1.732 \\
\hline Duration of paddle in water & 4.085 & $\mathbf{0 . 1 4 6}$ & 3.787 & $\mathbf{0 . 1 4 2}$ & $5.315^{*}$ \\
\hline
\end{tabular}

Table (5) indicates statistically significant differences on Boat speed, Stroke frequency, Boat speed during stroke (paddle cycle) and Duration of paddle in water as ( $t$ ) calculated values ranged between 3.231 and $5.315(\mathrm{P} \leq 0.05)$.

\section{Discussion:}

Scientific research in physical education has become more and more important as it contributes greatly in solving problems related to junior athletes, their coaches and tools and equipments they use. Scientists try to help solving these problems as their contributions in this field are wellrecognized. Rowing is a sport that does not have sufficient attention in scientific research. Therefore, the researcher is trying to shed some light at this sport to encourage its practice and expand its practitioner base. Using equipments like the ergometer help mastering rowing skills in addition to its contribution in helping rowers to evaluate themselves and their potentials to understand their true performance level and improve it accordingly. This study is trying to identify the effects of using ergometers on improving the learning efficiency of young rowers.
Table (5) indicates statistically significant differences between the post-measurements of the experimental and control groups on Boat speed, Stroke frequency, Boat speed during stroke (paddle cycle) and Duration of paddle in water, in favor of the experimental group. The researcher thinks that this is due to the use of the ergometer as it resembles the real performance tool with the same mechanism of performance. Therefore, this improves the neural pathways and brain performance which in turn improves the rower's performance as if he/she is practicing more in water. The ergometer improved out-water and inwater performance as well. This decreases time and effort for practice in water and makes the rower more capable of performing in water due to the decrease of fear and the improved sequential progressive performance of the skills. This is in agreement with Reem Hassan (2002), Hazem Hassan (2005), Kane et al (2008) and Benson et al (2011) who indicated that training that is consistent with the motor skill and using the same motor pathways and working muscles affects performance positively as it saves time and effort to master the motor skills (5, 14, 12 and 7). 
Conclusions:

The researcher concluded that there are statistically significant differences between the post-measurements of the experimental and control groups on Boat speed, Stroke frequency, Boat speed during stroke (paddle cycle) and Duration of paddle in water, in favor of the experimental group as $(\mathrm{t})$ calculated values ranged between 3.231 and $5.315(\mathrm{P} \leq 0.05)$.

Recommendations:

The researcher recommends the following:

1. Applying the recommended educational program using the ergometer with advanced rowers due to its positive effects on performance

2. Using other aids and equipments that help improving learning and training rowers

References:

1. Abd El-Fattah, Abu Al-Ela \& Hasanain, Mohamed S. (1997): Physiology, morphology and methods of measurement and evaluation, $11^{\text {th }}$ ED. Dar Al-Fikr Al-Araby - Cairo - Egypt (in Arabic)

2. Abd El-Salam, Hussain A. (1999): Comparing the effects of some approaches for improving specific muscle strength on the achievement level of young rowers. PhD thesis, Faculty of Physical Education for Men - Alexandria University Egypt (in Arabic)

3. Abd El-Salam, Hussain A. (2010): Effectiveness of strength drills with specific concentration on physical variables and the digital level of $2000 \mathrm{~m}$ race in young rowers. Scientific Journal of Physical Education, no.39. Faculty of Physical Education for Men - Alexandria University Egypt (in Arabic)

4. Ahmed, Maisa F. (2005): Effects of using monomin drills on some physical abilities and its relation to the digital level of speed swimming in junior swimmers (14-15 years). Theories and Applications, no.54, Faculty of Physical Education for Men - Alexandria University Egypt (in Arabic)

5. Al-Desouquy, Reem, M. (2002): Effects of using specific exercises program on improving the handspring forward on the jumping horse. Masters thesis, Faculty of Physical Education for Men - Alexandria University - Egypt (in Arabic)

6. Al-Roquaiy, Ibrahim S. (2012): Predicting some functional and physical aspects using the rowing ergometer for young rowers. PhD thesis, Faculty of Physical Education for Men - Alexandria University - Egypt (in Arabic)
7. Benson, A., Abendroth, J., King, D., \& Swensen, T. (2011): Comparison of rowing on a Concept 2 stationary and dynamic ergometer. Journal of Sports Science and Medicine, 10, 267-273

8. Egyptian Federation of Rowing (2007): Rowing in 100 years. Al-Tobgy Press Cairo - Egypt (in Arabic)

9. Fritsch, w (1990): Hand Buch Fur das Remnrudern, Meyer Meyerverlag, Aachen

10. Hasanian, Mohamed S. (2004): Measurement and evaluation in physical education, part $2,6^{\text {th }}$ ED. Dar Al-Fikr Al-Araby - Cairo - Egypt (in Arabic)

11. Ismaeel, Magdy A. (1992): Designing a test battery for measuring physical fitness of Egyptian rowers. PhD thesis, Faculty of Physical Education for Men - Helwan University - Egypt (in Arabic)

12. Kane, D. A., Jensen, R. L., Williams, S. E., \& Watts, P. B. (2008): Effects of drag factor on physiological aspects of rowing. International journal of sports medicine, 29(05), 390-394

13. Klusiewicz, A., Faff, J., \& Sitkowski, D. (1998): Reproducibility of the results of the laboratory exercise performed on rowing ergometer. BIOLOGY OF SPORT, 15(3), 145150

14. Mahmoud, Hazem H. (2005): Effects of a training program using specific exercises on improving the technical level of the Highly Kid Skill on the parallel bars. Scientific Journal of Physical Education and Sports, no.4, Faculty of Physical Education - Mansoura University - Egypt (in Arabic)

15. Mustafa, Marwa A. (2010): Effects of sports exercises and dry ladder on improving the take off phase of the moving ladder and its relation to the performance level of some jumps in junior divers. PhD thesis, Faculty of Physical Education for Men - Helwan University - Egypt (in Arabic)

16. Omar, Mohamed S. (1981): Effects of modifying some parts of free-design boats on some mechanical aspects of rowing. $\mathrm{PhD}$ thesis, Faculty of Physical Education for Men - Alexandria University - Egypt (in Arabic)

17. Radwan, Mohamed N. (1998): Methods for measuring phusical effort. Markaz Al-Ketab Press, Cairo - Egypt (in Arabic)

18. Saif, Mustafa A. (2011): Effects of some specific exercioses on the effectiveness of rebound movement and its relation to the digital level of young rowers. Masters thesis, Faculty of Physical 
Education for Men - Alexandria University Egypt (in Arabic)

19. Shehata, Mohamed I. \& Berekaa, Mohamed G. (1996): Physical Measurements and Motor Performance Tests Guide. Munshaat Al-Maaref, Alexandria - Egypt (in Arabic)

20. Waly, Nasima M. (2001): Using the Photo-board in teaching the over head serve in volleyball and its effects on learning outcomes. Theories and Applications, no.41, Faculty of Physical Education for Men - Alexandria University Egypt (in Arabic)

21. Zaghloul, Mohamed S. \& Abu Harga, Makarem (2000): Problems of Physical Education Curricula. Markaz Al-Ketab Press, Cairo Egypt (in Arabic) 